\title{
High population differentiation in the rock-dwelling land snail (Trochulus caelatus) endemic to the Swiss Jura Mountains
}

\author{
Sylvain Ursenbacher · Caren Alvarez • \\ Georg F. J. Armbruster · Bruno Baur
}

Received: 9 February 2009/Accepted: 24 June 2009/Published online: 14 July 2009

(C) Springer Science+Business Media B.V. 2009

\begin{abstract}
Understanding patterns of genetic structure is fundamental for developing successful management programmes for isolated populations of threatened species. Trochulus caelatus is a small terrestrial snail endemic to calcareous rock cliffs in the Northwestern Swiss Jura Mountains. Eight microsatellite loci were used to assess the effect of habitat isolation on genetic population structure and gene flow among nine populations occurring on distinct cliffs. We found a high genetic differentiation among populations (mean $F_{\mathrm{ST}}=0.254$ ) indicating that the populations are strongly isolated. Both allelic richness and effective population size were positively correlated with the size of the cliffs. Our findings support the hypothesis that $T$. caelatus survived on ice-free cliffs during the Pleistocene glacier advancements from the Alps. Due to the establishment of beech and pine forest under recent, temperate climate conditions, dispersal between cliffs is no longer possible for rock-dwelling snails such as T. caelatus. Our results provide basic data for developing a conservation action plan for this endangered gastropod species.
\end{abstract}

Keywords Helicoidea - Land snails · Microsatellites · Population genetic structure $\cdot$ Trochulus caelatus

S. Ursenbacher $(\bowtie) \cdot$ C. Alvarez · G. F. J. Armbruster · B. Baur Department of Environmental Sciences, Section of Conservation Biology, University of Basel, St. Johanns-Vorstadt 10, 4056 Basel, Switzerland

e-mail: s.ursenbacher@unibas.ch

G. F. J. Armbruster

Botanisches Institut der Universität Basel, Schönbeinstrasse 6 , 4056 Basel, Switzerland

\section{Introduction}

The fragmentation of natural habitat is generally considered to be a major threat to many species. Population genetic theory predicts that the isolation of small populations lead to a reduction of genetic diversity. Human activities are often the main causes of habitat fragmentation, but geographical processes and/or specific habitat requirements may also contribute to natural segregation of populations. Species with limited dispersal ability particularly suffer from isolation, which may lead to a marked genetic divergence among populations (e.g. Conner and Hartl 2004). Furthermore, in isolated populations with decreasing population size, the risk of genetic drift increases which may lead to a reduction of genetic diversity (e.g. Frankham 2003) and an enhanced risk of inbreeding (Saccheri et al. 1998; Reed and Frankham 2003). Consequently, the evaluation of the extent of isolation of the existing populations and their genetic diversity are of major concern to assess the risk of disappearance of any threatened taxa.

Land snails are ideal model organisms to study population genetics of species with restricted dispersal ability. Several studies have focused on the micro-scaled structure of land snail populations (Schilthuizen and Lombaerts 1994; Anderson 2007; Armbruster et al. 2007a). Trochulus caelatus (formerly Trichia caelata) is a small terrestrial gastropod (shell height: $4 \mathrm{~mm}$, width: $8 \mathrm{~mm}$; Kerney et al. 1983) endemic to the northwestern Swiss Jura Mountains. This species is a highly specialised rock-dwelling snail restricted to limestone cliffs between 400 and 1,280 m above sea level with exposed rock faces resulting in an extremely patchy distribution in a small area (Turner et al. 1998). Due to its particular habitat requirements and the very limited distribution area, $T$. caelatus is considered as 
potentially threatened on the Red List of Switzerland (Turner et al. 1994). During the last glacier advancement, this gastropod survived in ice-free tundra regions (nunataks) in the Swiss Jura Mountains. The temperature increase during the Holocene led to the establishment of beech forest and this species had to retract to the last open areas such as rock cliffs. The present distribution of $T$. caelatus coincides largely with areas that were ice-free during the last glacier advancement from the Alps (Turner et al. 1998), suggesting that this snail has not spread since the last glaciation. The surrounding forest may strongly reduce or even prevent dispersal among distinct cliffs. Consequently, we can presume that gene flow (if occurring) is restricted among populations.

We first examined 132 cliffs in the distribution area of the species in order to determine where T. caelatus is still occurring. When sufficient numbers of individuals were observed, samples were collected and levels of genetic variation and differentiation were investigated using microsatellite markers. We also conducted landscape genetic analyses to determine whether population groups may occur and whether some evolutionary significant units (ESUs) or managements units (MUs; see Moritz 1994) can be determined. Our investigation will help to develop a conservation action plan for this rare gastropod.

\section{Material and methods}

Field survey and sampling

One hundred and twenty-two cliffs, spread over the entire distribution area of $T$. caelatus were examined for the presence of the species between April and August 2006 (Fig. 1). The cliffs examined were located at altitudes ranging from 380 to $1,360 \mathrm{~m}$ above sea level. They consist of Jurassic coral chalks. The cliff bases are covered by different stands of deciduous forests belonging to Fagetum and Tilietum associations (Burnand and Hasspacher 1999).

One sampling plot ( $2 \mathrm{~m}$ high and $10 \mathrm{~m}$ long) was randomly placed along the foot of a cliff. A cliff was
Fig. 1 Locations of the cliffs examined for Trochulus caelatus. Solid dots indicate cliffs where the species was found, open dots indicate cliffs where the species was not found and grey dots to populations analysed in this study

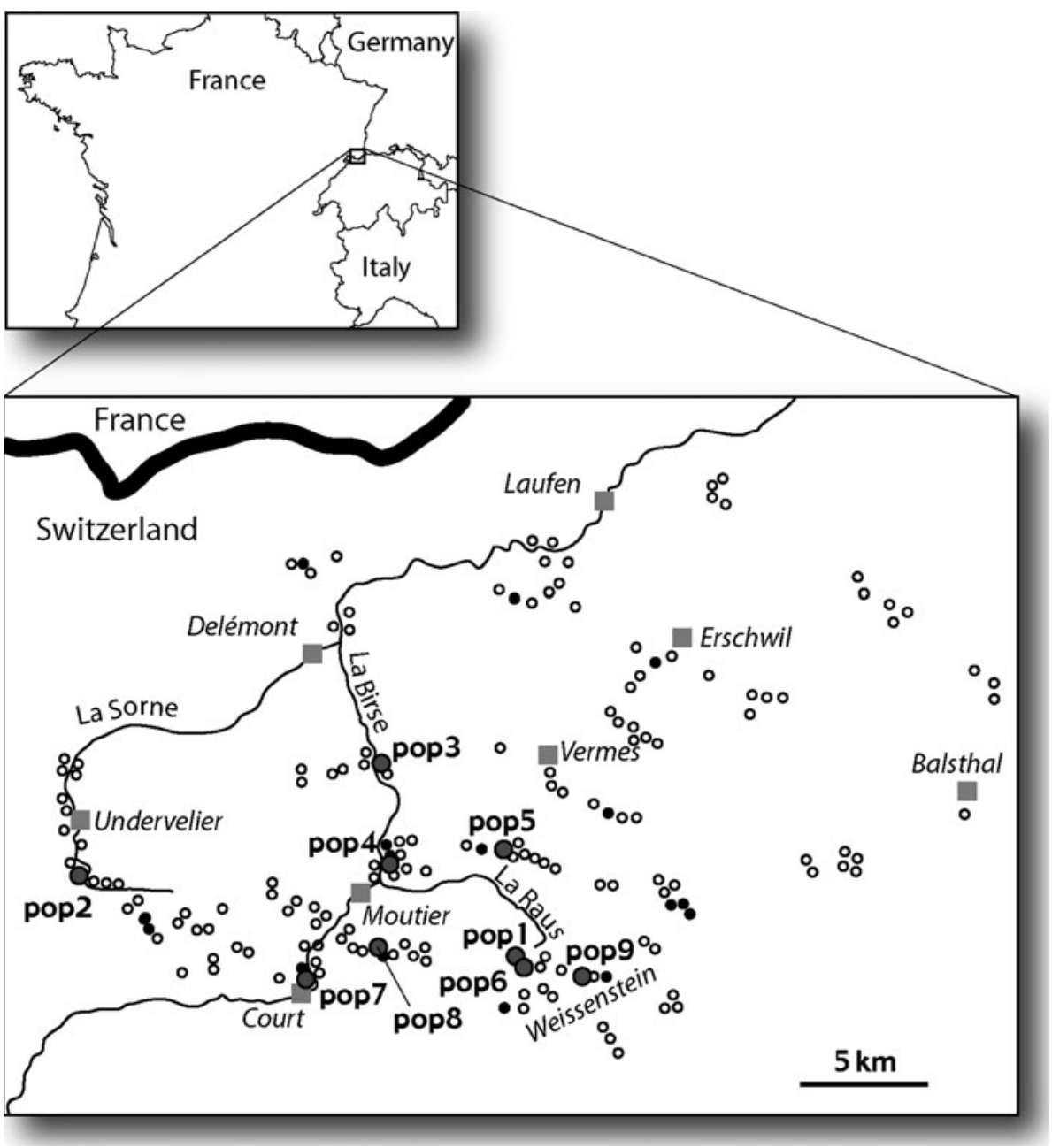


considered as an isolated unit when it was separated from neighbouring cliffs by a strip of soil $(>2 \mathrm{~m})$ covered with vegetation. In each plot, the vertical rock surface, fissures and pockets were carefully searched for T. caelatus for $10 \mathrm{~min}$., and the number of individuals was recorded. The presence of other snail species (Trochulus montanus, Pyramidula rupestris, Cochlostoma septemspirale, Chondrina avenacea and Abida secale) was also noted. Possible associations between species were tested using Chi-square tests. For each cliff the following variables were recorded: altitude (in metres above sea level), the horizontal length of the cliff (with five categories: $\leq 10,11-20,21-50,51-100$ and $>100 \mathrm{~m}$ ), the height of the cliff (three categories: $\leq 5,5-10$ and $>10 \mathrm{~m}$ ), the size of a cliff (calculated by cliff length $x$ cliff height), exposure of the cliff face, number of trees occurring at distances of 0-5 and 5-10 m from the cliff's foot and the cliff area (\%) covered by grass and moss. Relations between occurrence of $T$. caelatus and cliffs parameters were tested using Chi-square tests and logistic regressions. For conservation reasons, samples of ten snails were only taken in the nine largest populations. Snail sampling was conducted on another day than the density estimate.

\section{DNA extraction and microsatellite amplification}

Collected snails were stored at $-80^{\circ} \mathrm{C}$. Genomic DNA was extracted from the whole soft body of the snail using the DNeasy Blood \& Tissue Kit (Qiagen). DNA concentration was measured with a NanoDrop ${ }^{\circledR}$ ND-1000 UV-Vis Spectrophotometer (Thermo Fisher Scientific) and the DNA samples were diluted to a standard concentration of $10 \mathrm{ng} / \mu \mathrm{l}$.

Eight microsatellite loci (primers 08, 09, 10, 13, 16, 18, 22 and 26) developed for T. caelatus were used (Armbruster et al. 2007b). PCR was performed in $25 \mu$ volume following the protocol described by Armbruster et al. (2007b). Spreadex EL-400 or EL-600 gels (Elchrom Scientific AG, Switzerland) were used to resolve allelic patterns by horizontal electrophoresis performed on SEA 2000 advanced submerged gel electrophoresis equipment using M3 size marker (Elchrom Scientific AG, Switzerland; see Armbruster et al. 2005).

\section{Microsatellite analyses}

Microsatellite results of each population were checked for null alleles and mis-scoring using MICRO-CHEKER version 2.2.3 (Van Oosterhout et al. 2004). GenePop version 4.0 was applied to assess the null allele frequency for each locus in all populations (Raymond and Rousset 1995; Rousset 2008). We estimated allele frequency, allelic richness $\left(A_{\mathrm{R}}\right)$, observed and expected heterozygosity $\left(H_{\mathrm{O}}, H_{\mathrm{E}}\right)$ using Fstat version 2.9.3 (Goudet 1995). Heterozygote deficit within populations $\left(F_{\text {IS }}\right)$ was estimated and divergence from Hardy-Weinberg (HW) equilibrium was tested using FSTAT with 1,000 permutations. Effective population size $\left(N_{\mathrm{e}}\right)$ was estimated using the linkage disequilibrium method proposed by Bartley et al. (1992) implemented in NeEstimator version 1.1.1 (Peel et al. 2004). Spearman's rank correlations were calculated to examine relationships between genetic diversity (i.e. allelic richness; $A_{\mathrm{R}}$ ), effective population size and environmental parameters (cliff size and snail abundance).

Genetic relationships within and among populations were investigated using FSTAT to estimate $F$-statistics (Weir and Cockerham 1984). Isolation by distance was tested using Mantel's test (Mantel 1967) by comparing pairwise $\left(F_{\mathrm{ST}} /\left(1-F_{\mathrm{ST}}\right)\right)$ values with the corresponding geographic distances (log-transformed) using the program Fsтат. This transformation has been showed to be more accurate in detecting isolation by distance than $F_{\mathrm{ST}}$ versus untransformed geographic distance (Rousset 1997).

In addition, Bayesian individual assignment approach as implemented in Structure version 2.2.3 (Pritchard et al. 2000) was tested using a model of admixture with a number of populations $(K)$ ranging from 1 to 12 . Likelihood values for ten replicates of each $K$ value were estimated after 150,000 iterations (with the first 50,000 iterations discarded as burn-in). The best $K$ value was chosen by applying the method of Evanno et al. (2005) which considers a second order rate of change to determine the most likely value of $K$.

\section{Results}

\section{Habitat characteristics}

Individuals of $T$. caelatus were found in 24 of the 122 (19.7\%) plots examined (Fig. 1). The 24 populations were situated at an altitudinal range of $460-1,360 \mathrm{~m}$ in an area of $25 \mathrm{~km} \times 20 \mathrm{~km}$. T. caelatus occurred more frequently on large cliffs (cliff length $>50 \mathrm{~m}$ ) than on small cliffs $\left(\chi^{2}=5.21, d f=1, P=0.023\right)$. Furthermore, the occurrence of $T$. caelatus was positively associated with a presence of $C$. avenacea or A. secale $\left(\chi^{2}=4.26, d f=1\right.$, $P=0.039)$ and negatively associated with the number of trees at a distance of 5-10 m from the cliff's foot (logistic regression: odd ratio $=0.461$ (95\% CI: 0.243-0.875), $P=0.016$ ). The presence of $T$. caelatus was, however, neither affected by cliff height, altitude, exposure of the cliff face, and the percentages of the rock surface covered by grass and moss (in each case $P>0.1$ ). Interestingly, T. caelatus was found on cliffs exposed to all directions. 
On most cliffs the abundance of $T$. caelatus was low. At 13 out of 24 sites (54.2\%) only 1-5 individuals were found during $10 \mathrm{~min}$. of searching. The largest numbers of snails per plot was 24 during a 10 min search period.

Population genetic diversity

Between 6 (P13) and 23 (P08) alleles were observed in the 90 individuals analysed in nine populations. Using MicRoCHECKER, possible occurrence of null alleles was detected for locus P18 in one population, for P08, P10, P13 and P26 in two populations and for locus P16 in four populations. Allelic richness within populations varied between 2.91 (Pop 5) and 4.64 (Pop 8) (Table 1). The frequency of null alleles per population estimated with GenePoP ranged from 0 to 0.450 . Considering single primers, mean null allele frequency varied from 0 (locus P09) to 0.145 (locus P13). Four of eight markers showed significant deviations from HW equilibrium (P10, P13, P16 and P26). Consequently, $H_{\mathrm{O}}, H_{\mathrm{E}}$ and $F$-statistics were calculated on the basis of the remaining four microsatellite markers (P08, P09, P18 and P22; Table 1). Estimates of the effective population size varied between 5.7 (Pop 5) and 25.9 (Pop 2). However, no estimates were available for Pop 3 and Pop 9 with the linkage disequilibrium method (Table 1).

Significant positive relationships between cliff size and allelic richness (Spearman's test: $r_{\mathrm{s}}=0.73, n=9$, $P=0.024)$ and cliff size and effective population size

Table 1 Genetic diversity in nine populations of the snail Trochulus caelatus endemic to the Swiss Jura Mountains

\begin{tabular}{lrlllllll}
\hline Population & $N_{\mathrm{f}}$ & $N_{\mathrm{A}}$ & $A_{\mathrm{R}}$ & $H_{\mathrm{O}}$ & $H_{\mathrm{E}}$ & \multicolumn{1}{l}{$F_{\mathrm{IS}}$} & $N_{\mathrm{e}}$ & $95 \% \mathrm{CI}$ \\
\hline Pop 1 & 15 & 10 & 4.11 & 0.725 & 0.674 & -0.076 & 25.5 & $12.4-240$ \\
Pop 2 & 15 & 10 & 4.13 & 0.575 & 0.537 & -0.070 & 25.9 & $12.7-220$ \\
Pop 3 & 15 & 10 & 4.33 & 0.544 & 0.711 & 0.235 & $\mathrm{NA}$ & - \\
Pop 4 & 20 & 10 & 3.79 & 0.625 & 0.718 & 0.130 & 7.1 & $4.9-11.4$ \\
Pop 5 & 24 & 10 & 2.91 & 0.500 & 0.526 & 0.050 & 5.7 & $3.6-10.4$ \\
Pop 6 & 16 & 10 & 3.28 & 0.575 & 0.628 & 0.084 & 8 & $5.0-15.4$ \\
Pop 7 & 5 & 10 & 4.37 & 0.700 & 0.736 & 0.049 & 15.9 & $9.0-46.3$ \\
Pop 8 & 16 & 10 & 4.64 & 0.625 & 0.7375 & 0.153 & 14.4 & $9.2-27.9$ \\
Pop 9 & 11 & 10 & 4.53 & 0.800 & 0.693 & -0.15 & NA & - \\
\hline
\end{tabular}

$N_{\mathrm{f}}$ corresponds to the number of snails found in an area of $20 \mathrm{~m}^{2}$ within $10 \mathrm{~min}$ of search, indicating the population density. $N_{\mathrm{A}}$ corresponds to the number of snails genetically analysed. Allelic richness $\left(A_{\mathrm{R}}\right)$ was estimated for six diploid individuals for all eight loci. Observed and expected heterozygosity $\left(H_{\mathrm{O}}\right.$ and values $\left.H_{\mathrm{E}}\right)$, and heterozygote deficit within populations $\left(F_{\text {IS }}\right)$ were estimated on the basis of the four loci in Hardy-Weinberg equilibrium. Effective population size estimates $\left(N_{\mathrm{e}}\right)$ with the $95 \%$ confidence interval $(\mathrm{CI})$ were calculated using the linkage disequilibrium method implemented in NeEstimator (Peel et al. 2004)

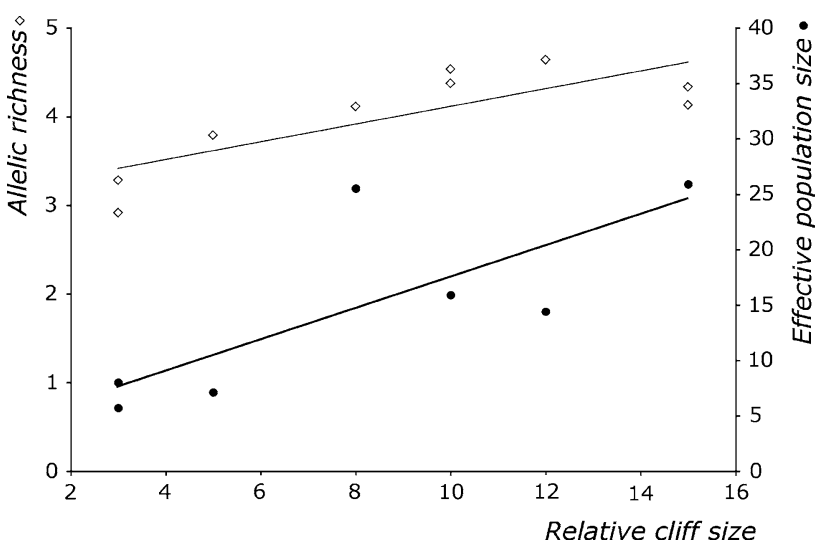

Fig. 2 Relationships between cliff size (height $\times$ length) and allelic richness based on eight microsatellite markers in nine populations of Trochulus caelatus (left scale and open diamonds; Spearman's rank correlation: $\left.r_{\mathrm{s}}=0.73, n=9, P=0.024\right)$ and cliff size and effective population size calculated using genetic markers with a linkage disequilibrium method implemented in NeEstimator (Peel et al. 2004) (right scale and full dots; $r_{\mathrm{s}}=0.88, n=7, P=0.008$ )

$\left(r_{\mathrm{s}}=0.88, n=7, P=0.008\right)$ were found (Fig. 2). Furthermore, a marginally significant negative relationship between snail abundance and allelic richness was found $\left(r_{\mathrm{s}}=-0.64, n=9, P=0.064\right)$.

\section{Population differentiation}

High genetic differentiation was observed among the populations examined (mean $F_{\mathrm{ST}}=0.254$ ). All pairwise $F_{\mathrm{ST}}$-values were significant (Table 2 ). The lowest value (0.099) was found between Pop 1 and Pop 6, which are isolated by only $100 \mathrm{~m}$ of unfavourable habitat. Isolation by distance was found (Mantel test: $r^{2}=0.213, n=36$, $P=0.011$, even if the fraction of genetic divergence explained by distance is limited.

The number of population groups was estimated to $K=2$ using the method of Evanno et al. (2005). The populations 1, 5, 6 and 9 belong to one cluster, the populations 2, 3, 4, 7 and 8 to another. A sub-structure was detected in the first group. The program Structure suggested three sub-populations (one consisting of Pop 5, Pop 6 and Pop 9; one of four individuals of Pop 1 being regrouped with Pop 9 and one of six individuals of pop 1 together with Pop 6) and five sub-populations in the second group, each consisting of a distinct population (Pop 2, Pop 3, Pop 4, Pop 7, Pop 8).

\section{Discussion}

The field survey showed that the distribution of the endemic $T$. caelatus is restricted to a moderate number of small 
Table 2 Pairwise $F_{\mathrm{ST}}$ estimates based on the analysis of four microsatellite loci in nine populations of the snail Trochulus caelatus endemic to the Swiss Jura Mountains

\begin{tabular}{|c|c|c|c|c|c|c|c|c|}
\hline & Pop 2 & Pop 3 & Pop 4 & Pop 5 & Pop 6 & Pop 7 & Pop 8 & Pop 9 \\
\hline Pop 1 & $0.275 * *$ & 0.263 & 0.231 & 0.339 & $0.099 * *$ & 0.197 & $0.202 * *$ & $0.120 * *$ \\
\hline Pop 2 & & $0.321 * *$ & 0.361 & $0.458 * *$ & $0.337 * *$ & $0.187 * *$ & 0.299 & 0.302 \\
\hline Pop 3 & & & $0.230 * *$ & 0.307 & $0.216^{* *}$ & $0.147 * *$ & 0.197 & 0.263 \\
\hline Pop 4 & & & & 0.335 & $0.221 * *$ & $0.243 * *$ & 0.178 & $0.216^{* *}$ \\
\hline Pop 5 & & & & & $0.383 * *$ & $0.305 * *$ & $0.311 * *$ & 0.307 \\
\hline Pop 6 & & & & & & $0.266 * *$ & 0.182 & $0.127 * *$ \\
\hline Pop 7 & & & & & & & 0.169 & $0.229 * *$ \\
\hline Pop 8 & & & & & & & & $0.165^{* *}$ \\
\hline
\end{tabular}

Significance was calculated with Fstat (Goudet 1995) using 36'000 permutations. ${ }^{*} * P<0.01$; for all other pairwise estimates, $P<0.005$

populations in an area of $25 \times 20 \mathrm{~km}$. Relating the number of cliffs examined (122) to the number of cliffs existing in this region of the Jura Mountains, we assume that we have found $30-50 \%$ of the extant populations.

The analysis of genetic markers revealed a high degree of genetic differentiation between the examined $T$. caelatus populations, even in populations separated by less than $100 \mathrm{~m}$. The results of individual oriented analysis (STRUCTURE) suggest a very restricted amount of gene flow between most populations. Trochulus caelatus is a rockdwelling species living on vertical rock faces. The snail does not occur in the leaf litter of the forests surrounding the cliffs (Alvarez 2005). Considering the limited dispersal ability as indicated by the genetic analyses and by direct observations in other rock-dwelling snails (e.g. a maximum dispersal of $2.64 \mathrm{~m}$ per year was observed in Chondrina clienta; Baur and Baur 1995), we can conclude that most current populations are completely isolated. Between a few populations (Pop 1, Pop 6 and Pop 9), however, a low level of genetic differentiation was detected. The STRUCTURE analysis was not able to completely separate these populations which are situated about $100 \mathrm{~m}$ apart. Hence, we presume that a few gene exchanges might have occurred between these populations in the last decades.

Microsatellite markers have rarely been used to examine the population genetic structure of land snail species. In the closely related species Trochulus villosus a mean $F_{\mathrm{ST}}$ of 0.159 between 20 sites (maximum distance between sites: $300 \mathrm{~km}$ ) has been reported (Dépraz et al. 2008). In Helix aspersa and Cepaea nemoralis, two snail species with larger shells, $F_{\mathrm{ST}}$ values of respectively 0.093 and 0.076 were found (Arnaud and Laval 2004; Schweiger et al. 2004). Trochulus villosus lives in the ground vegetation of deciduous forests, a habitat that frequently extends over hundreds of metres. Nevertheless, a continuous distribution of $T$. villosus seems to reduce the genetic divergence between sites probably due to gene flow. For isolated populations, high $F_{\text {ST }}$ values were observed among nearby populations in $H$. aspersa, $C$. nemoralis and $T$. caelatus. The $F_{\mathrm{ST}}$ values were slightly higher in $T$. caelatus than in the other species. However, this does not indicate a significant higher genetic differentiation compared to other land snail species.

Numerous other land snail species have small distribution areas with isolated populations. For example, Trochulus biconicus is endemic to a small mountain area in the Swiss Alps (M. Baggenstross, personal communication). Arianta aethiops occurs at a few localities in the southern Carpathian Mountains, Romania (Baur et al. 2000), and various land snails can be found on single carstic towers in Malaysia (Clements et al. 2008). Knowledge of genetic differentiation of the extant and mostly isolated populations of snail species with small distribution areas is extremely important for the success of future conservation and restoration actions.

Results of both population genetic and capture-markrecapture studies (e.g. Arianta arbustorum, Baur 1986; Albinaria corrugata, Schilthuizen and Lombaerts 1994) confirm dispersal distances of only a few metres per year (not considering passive dispersal) in terrestrial snails. Long distance dispersal events due to passive transportation by wind, water, avalanches, mammals and birds are rare in land snails (Bengtsson and Baur 1993; Baur et al. 1997; Akçakaya and Baur 1996) and most probably insufficient to maintain gene flow between otherwise isolated populations. Furthermore, isolation by distance as found in this study suggests that the probability of passive dispersal is related to the distance between populations.

During the last glacial advancement, $T$. caelatus survived in ice-free sites in the Jura Mountains and did not spread afterwards (Turner et al. 1998). The lack of dispersal, combined with a limited number of ice-free sites in the Jura Mountains (Stehlik et al. 2001, 2002; Schönswetter et al. 2005; Dépraz 2008) may explain the current distribution. We also found a positive association between cliff size and both genetic diversity and effective population size (in 
contrast to Discus macclintocki, also a relict snail; Ross 1999). This finding implies the occurrence of numerous small refugia for $T$. caelatus during the last glaciation. Finally, the restricted dispersal may have limited the postglacial colonisation of cliffs released from the ice sheet during the Holocene.

\section{Conservation suggestions}

The significant genetic differentiation of the populations examined and the snails' restricted dispersal ability indicate that current populations are completely isolated when they are separated by more that $200 \mathrm{~m}$. Consequently, all these populations should be treated and protected as separated units (Management Units). The severe fragmentation of this endemic snail species, its small distribution area and the small population sizes strongly increase the risk of local and global extinction.

Changes in forestry practice (e.g. clear-cutting), which alter the lichen, moss and plant communities on the cliff walls, as well as rock climbing are the major threats to $T$. caelatus. Various specialised land snail species inhabiting rock cliffs in the Jura Mountains are negatively affected by climbing activities (B. Baur, unpublished data). The prohibition of sport climbing on cliffs with endangered land snails, lichens and plants is the most effective and adequate measure to preserve these species.

Small populations are also exposed to a high risk of extinction due to environmental or demographic stochasticity. Moreover, the relationship between cliff size and allelic richness indicates an increased risk of inbreeding and the occurrence of negative effects of inbreeding depression in small sites, and consequently a threat of disappearance of some populations. Because (re)colonisation of favourable habitats is restricted to extremely rare events of passive dispersal, the present population structure cannot be considered as a metapopulation complex. Therefore, any loss of a population would have a considerable impact on the survival of the endemic $T$. caelatus in the long-term.

Acknowledgments We thank Peter Stoll for statistical advice and Hans-Peter Rusterholz, Anette Baur, Paul L. Leberg and two anonymous reviewers for comments on the manuscript.

\section{References}

Akçakaya HR, Baur B (1996) Effects of population subdivision and catastrophes on the persistence of a land snail metapopulation. Oecologia (Berl.) 105:475-483

Alvarez C (2005) Habitat requirements and population differentiation in the land snail Trichia caelata endemic to the Swiss Jura Mountains. Master thesis, University of Basel
Anderson FE (2007) Population genetics of the carinate pillsnail, Euchemotrema hubrichti: genetic structure on a small spatial scale. Conserv Genet 8:965-975

Armbruster GFJ, Koller B, Baur B (2005) Foot mucus and periostracum fraction as non-destructive source of DNA in the land snail Arianta arbustorum, and the development of new microsatellite loci. Conserv Genet 6:313-316

Armbruster GFJ, Hofer M, Baur B (2007a) Effect of cliff connectivity on the genetic population structure of a rock-dwelling land snail species with frequent self-fertilization. Biochem Syst Ecol 35: 325-333

Armbruster GFJ, Alvarez C, Pesaro M, Baur B (2007b) Polymorphic microsatellite DNA markers in the endangered land snail, Trichia caelata (Gastropoda, Stylommatophora). Mol Ecol Notes 7: $1123-1124$

Arnaud JF, Laval G (2004) Stability of genetic structure and effective population size inferred from temporal changes of microsatellite DNA polymorphisms in the land snail Helix aspersa (Gastropoda : Helicidae). Biol J Linn Soc 82:89-102

Bartley D, Bagley M, Gall G, Bentley B (1992) Use of linkage disequilibrium data to estimate effective size of hatchery and natural fish populations. Conserv Biol 6:365-375

Baur B (1986) Patterns of dispersion, density and dispersal in alpine populations of the land snail Arianta arbustorum (L.) (Helicidae). Holarct Ecol 9:117-125

Baur B, Baur A (1995) Habitat-related dispersal in the rock-dwelling land snail Chondrina clienta. Ecography 18:123-130

Baur B, Ledergerber S, Kothbauer H (1997) Passive dispersal on mountain slopes: shell shape-related differences in downhill rolling in the land snails Arianta arbustorum and Arianta chamaeleon (Helicidae). Veliger 40:84-85

Baur B, Schileyko AA, Baur A (2000) Ecological observations on Arianta aethiops aethiops (Helicidae), a land snail endemic to the South Carpathian mountains. J Molluscan Stud 66:285-289

Bengtsson J, Baur B (1993) Do pioneers have r-selected traits? Lifehistory patterns among colonizing terrestrial gastropods. Oecologia (Berl.) 94:17-22

Burnand J, Hasspacher B (1999) Waldstandorte beider Basel. Kommentar zur vegetationskundlichen Standortskartierung der Wälder. Verlag des Kantons Basel-Landschaft, Liestal

Clements R, Ng PKL, Lu XX, Ambu S, Schilthuizen M, Bradshow CJA (2008) Using biogeographical patterns of endemic land snails to improve conservation planning for limestone karsts. Biol Conserv 141:2751-2764

Conner JK, Hartl DL (2004) A primer of ecological genetics. Sinauer Associates, Inc., Sunderland

Dépraz A (2008) Low dispersing species: population genetic processes in space and time-the genus Trochulus (Gastropoda: Hygromiidae) as a case study. $\mathrm{PhD}$, University of Lausanne

Dépraz A, Cordellier M, Hausser J, Pfenninger M (2008) Postglacial recolonisation at a snail's pace (Trochulus villosus): confronting competing refugia hypotheses using model selection. Mol Ecol 17:2449-2462

Evanno G, Regnaut S, Goudet J (2005) Detecting the number of clusters of individuals using the software STRUCTURE: a simulation study. Mol Ecol 14:2611-2620

Frankham R (2003) Genetics and conservation biology. C R Biol 326:S22-S29

Goudet J (1995) FSTAT (version 1.2): a computer program to calculate F-statistics. J Hered 86:485-486

Kerney MP, Cameron RAD, Jungbluth JH (1983) Die Landschnecken Nord- und Mitteleuropas. Paul Parey Verlag, Hamburg

Mantel N (1967) Detection of disease clustering and a generalized regression approach. Cancer Res 27:209

Moritz C (1994) Defining "evolutionarily significant units" for conservation. Trends Ecol Evol 9:373-375 
Peel D, Ovenden JR, Peel SL (2004) NeEstimator: software for estimating effective population size. Queensland Government, Department of Primary Industries and Fisheries, Brisbane, Australia, Ver. 1.1.1

Pritchard JK, Stephens M, Donnelly P (2000) Inference of population structure using multilocus genotype data. Genetics 155:945-959

Raymond M, Rousset F (1995) Genepop (version-1.2)—populationgenetics software for exact tests and ecumenicism. J Hered $86: 248-249$

Reed DH, Frankham R (2003) Correlation between fitness and genetic diversity. Conserv Biol 17:230-237

Ross TK (1999) Phylogeography and conservation genetics of the Iowa Pleistocene snail. Mol Ecol 8:1363-1373

Rousset F (1997) Genetic differentiation and estimation of gene flow from $F$-statistics under isolation by distance. Genetics 145:12191228

Rousset F (2008) GENEPOP'007: a complete re-implementation of the GENEPOPsoftware for Windows and Linux. Mol Ecol Resour 8:103-106

Saccheri I, Kuussaari M, Kankare M, Vikman P, Fortelius W, Hanski I (1998) Inbreeding and extinction in a butterfly metapopulation. Nature 392:491-494

Schilthuizen M, Lombaerts M (1994) Population structure and levels of gene flow in the mediterranean land snail Albinaria corrugata (Pulmonata: Clausiliidae). Evolution Int $\mathrm{J}$ org Evolution 48: 577-586
Schönswetter P, Stehlik I, Holderegger R, Tribsch A (2005) Molecular evidence for glacial refugia of mountain plants in the European Alps. Mol Ecol 14:3547-3555

Schweiger O, Frenzel M, Durka W (2004) Spatial genetic structure in a metapopulation of the land snail Cepaea nemoralis (Gastropoda: Helicidae). Mol Ecol 13:3645-3655

Stehlik I, Schneller JJ, Bachmann K (2001) Resistance or emigration: response of the high-alpine plant Eritrichium nanum (L.) Gaudin to the ice age within the Central Alps. Mol Ecol 10:357-370

Stehlik I, Blattner FR, Holderegger R, Bachmann K (2002) Nunatak survival of the high Alpine plant Eritrichium nanum (L.) Gaudin in the central Alps during the ice ages. Mol Ecol 11:2027-2036

Turner H, Wüthrich M, Rüetschi J (1994) Rote Liste der gefährdeten Weichtiere der Schweiz. In: Duelli P (ed) Rote Listen der gefährdeten Tierarten in der Schweiz. Bundesamt für Umwelt, Wald und Landschaft, Bern

Turner H, Kuiper JGJ, Thew N, Bernasconi R, Rüetschi J, Wüthrich M, Gosteli M (1998) Atlas der Mollusken der Schweiz und Liechtensteins. Fauna Helv 2:342-343

Van Oosterhout C, Hutchinson WF, Wills DPM, Shipley P (2004) MICRO-CHECKER: software for identifying and correcting genotyping errors in microsatellite data. Mol Ecol Notes 4: $535-538$

Weir BS, Cockerham CC (1984) Estimating F-statistics for the analysis of population structure. Evolution Int $\mathbf{J}$ org Evolution 38:s1358-s1370 